\title{
¿UNA NUEVA CONSTITUCIÓN POLÍTICA MEXICANA?
}

\author{
JAIME ARTURO VERdín PÉREZ ${ }^{1}$
}

Resumen: Con base en el nuevo parámetro interpretativo resultante de las transformaciones políticas en nuesto país, que sirven como referencia al hablar de una posición privilegiada de la Constitución Política como ordenamiento jurídico con un alto contenido progresivo de derechos y libertades fundamentales a partir de la enmienda constitucional de 2011, en materia de derechos humanos y sobre la que existe un influjo considerable de normas provenientes de un sistema internacional que permiten una amplia protección para los derechos y libertades de las personas, nos obliga a cuestionarnos si es necesario que exista ¿una nueva Constitución Política?.

Además de ello, resulta indispensable cuestionar la vigencia, oportunidad, eficacia y fuerza normativa de la Constitución vigente a partir de 1917, considerando que la Constitución tiene normas de organización, de garantías y de procedimiento que obliga a hacer primar su obediencia, permitiendo con ello, el respeto de los derechos fundamentales y su capacidad de adaptación al cambio social.

Palabras Clave: Constitución, vigencia, interpretación, convencionalidad, fuerza normativa, reordenación.

ABSTRACT: Based on the new interpretive parameter resulting from the political transformations in our country, which serve as reference when speaking of a privileged position of the Political Constitution as a legal order with a high progressive content of rights and fundamental freedoms from the amendment constitutional of 2011, on human rights and on which there is a considerable influx of rules from an international system that allow a broad protection for the rights and freedoms of people, forces us to question whether there is a need for a new Political constitution?. In addition, it is essential to manage the validity, timeliness, effectiveness and

1 UNAM, Programa de Becas Posdoctorales de la UNAM. Becario del Instituto de Investigaciones Jurídicas de la UNAM, asesorado por el Dr. Eduardo Ferrer Mac-Gregor Poisot. Doctor en Derecho, Maestro en Derecho Constitucional y Amparo. Profesor y académico especialista en materia electoral del Posgrado en Derecho de la UNAM. 
normative force of the Constitution in force since 1917, considering that the Constitution has rules of organization, guarantees and procedures that obliges its obedience to prevail, thus allowing, respect for fundamental rights and their ability to adapt to social change.

KeYwords: Constitution, validity, interpretation, conventionality, normative force, reordering.

Sumario: I. Exordio; II. Fragmentación constitucional y la necesidad de un nuevo texto; III. La Constitución convencionalizada; IV. Contenido de una nueva Constitución; V. Conclusiones; VI. Bibliografía.

\section{EXORDIO}

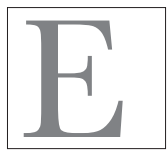

l presente documento tiene por objetivo general dilucidar en torno a la pregunta, ¿una nueva Constitución Política?, sobre todo considerando las actuales transformaciones políticas y jurídicas acontecidas recientemente en nuestro país, para lo cual, sirva de parámetro de referencia, por un lado, hablar de la constitución cuya posición privilegiada en el ordenamiento jurídico, y con un alto contenido progresivo en derechos y libertades fundamentales, se asumió como una "nueva Constitución" a la luz de la enmienda constitucional de 2011, en materia de derechos humanos y sobre la que existe un influjo considerable de normas provenientes de un sistema internacional que permiten una amplia protección para los derechos y libertades de las personas.

A partir de ese dato se explica que la interpretación que se realice de las normas, deberá ser de conformidad con la Constitución y los Tratados Internacionales, favoreciendo en todo tiempo la interpretación más amplia a las personas. Este proceso de evolución de las disposiciones constitucionales debe entenderse como un proceso de adaptación a la realidad política y social. 
También es necesario, por otro lado, cuestionar la vigencia, oportunidad, eficacia y fuerza normativa de nuestra disposición fundamental de 1917, en su caso, el prestigio como norma de reconocimiento de derechos, su excesivo reformismo y su posible desnaturalización como derecho de mayor valor y que nos invita a debatir su quebrantamiento como norma fundacional de una comunidad política.

Recordemos que la Constitución tiene normas de organización, de garantías y de procedimiento que obliga a hacer primar su obediencia, permitiendo con ello, el respeto de los derechos fundamentales y su capacidad de adaptación al cambio social.

Antes de señalar con detenimiento el tema de análisis, conviene indicar que existen diversas problemáticas en torno a la idea de "Constitución", algunas de ellas que llevan a las crisis sobre la dimensión de la propia teoría constitucional y sus postulados, sobre todo por la inclusión de los derechos humanos, contemplando la transfiguración de órganos de naturaleza constitucional, judicial o cuasijudicial, por influjo del derecho convencional. Esto es, la nuestra se concibe como una nueva carta convencionalizada.

Quizá resultará plausible el estudio sobre el control de convencionalidad, la teoría trasnacional y sus influjos hacia el derecho constitucional, dicha teoría entendida como concepto que se ha utilizado de manera muy vasta en el estudio de la economía, en temas de globalización y que en su momento propició en este ámbito material, la idea clara de un fenómeno de internacionalización del derecho constitucional.

Conviene precisar que el primero en utilizar este término - transnacional- en el ámbito del derecho, fue el Juez de la Corte Internacional de Justicia Philip Jessup, quien en 1956 publicó su famoso libro denominado Derecho Transnacional ${ }^{2}$ en el que discurre en torno

2 Jessup C. Philip, Transnational Law, Yale University Press, Geoffrey Cumberlege, Oxford, New Haven, 1956, p. 113. 
a diversos problemas jurídicos que él considera universales. Pero lo cierto es que, en la actualidad, la utilización de este vocablo en la ciencia del derecho es considerablemente común, como se ha adelantado también ha permeado en la idea constitucional.

La experiencia en la materia, nos permite cuestionar los contenidos sustantivos de la norma fundamental, afirmar que además, hoy es susceptible de recibir al derecho internacional de los derechos humanos y el control de convencionalidad. Este último entendido como propio, original o externo y que recae en un tribunal supranacional llamado a ejercer la confrontación entre actos domésticos y disposiciones convencionales, con la finalidad de apreciar la compatibilidad entre aquéllos y éstas, bajo el imperio del Derecho Internacional de los Derechos Humanos, y resolver la contienda a través de una sentencia declarativa y condenatoria, que en su caso, corresponda. ${ }^{3}$ Este postulado permite la erosión de la conciencia constitucional dada por el constituyente originario y motiva la fragmentación de nuestro texto genuino.

En cuanto al tema de examen, podría además englobar aspectos procesales y sustantivos, que adelantan en la dirección como respuesta al problema, la creación de un nuevo documento constitucional, que resulte compatible con algunos conceptos tales como el bloque de constitucionalidad, que la propia doctrina ha denominado como "principios y reglas de valor constitucional", ${ }_{4}^{4}$ pero que además se ha fortalecido por la interpretación de los tribunales constitucionales en el cumplimiento fiel de las obligaciones asumidas por el mismo

3 Sergio García Ramírez, "El control judicial interno de convencionalidad", en Eduardo Ferrer Mac-Gregor, El control difuso de convencionalidad. Diálogo entre la Corte Interamericana de Derechos Humanos y los jueces Nacionales, México, Fundap, 2012, p. 213.

${ }^{4}$ Se sugiere revisar, J. Pardo Falcón, El Consejo Constitucional Francés, La Jurisdicción Constitucional en la Quinta República, Madrid, Centro de Estudios Constitucionales, 1990. 
texto constitucional, los compromisos internacionales y el respeto a los derechos que favorezcan su plena vigencia. ${ }^{5}$

En síntesis la idea de la fuerza normativa de la Constitución deberá evaluarse, como elemento connatural e indispensable para su observancia, vigencia y legitimidad, sobre todo en el marco de la conformación de otros procesos y deberes asumidos desde 2011, ejemplo de ello, la interpretación conforme, que tal como lo indica Susana Albanese, resulta indispensable una relación de compatibilidad entre las medidas aplicadas por las autoridades nacionales y los preceptos convencionales, entendiendo que los órganos nacionales a quienes les compete garantizar el libre y pleno ejercicio de los derechos de las personas que se encuentran bajo su jurisdicción, ${ }^{6}$ pero más allá permite construir una nueva dialéctica constitucional, que concuerda con la idea de la constitución viviente, que se aleja del intento de ser solo un documento que recoge buenas intenciones.

\section{il. Fragmentación y necesidad de un nuevo texto CONSTITUCIONAL}

Como es sabido, el texto constitucional mexicano ha sufrido diversas modificaciones, para ser precisos a la fecha del presente documento son 706,7 si bien se presume que en la mayoría de los casos han resultado de utilidad y permiten una mayor regulación de aspectos torales en un contexto de pluralidad política como el que actualmente vivimos, su dinámica de integración resulta similar a

5 Se sugiere revisar, César Astudillo, El bloque y parámetro de constitucionalidad en México, México, Tirant Lo Blanch, 2014.

6 Susana Albanese, (coord.), Opiniones consultivas y observaciones generales. Control de Convencionalidad, Buenos Aires, Ediar, 2011. pp. 18-19.

7 Honorable Cámara de Diputados, Reformas Constitucionales por Artículo Última reforma publicada en el Diario Oficial de la Federación el 15 de septiembre de 2017, <http: / / www.diputados.gob.mx/LeyesBiblio/ref/cpeum_art.htm>. Recuperada el $10 \mathrm{de}$ agosto de 2018. 
una excesiva reglamentación de una ley ordinaria lo que acarrea grandes problemas constitucionales, procesales y de certeza jurídica para las instituciones, autoridades y gobernados.

No obstante ello, se ha indicado en el preámbulo del presente escrito que la carta fundante representa una norma de reconocimiento del Estado, sus reglas de actuación y la existencia de los derechos humanos se constriñen a su propia naturaleza y se sujetan a procedimientos especializados para su modificación, dificultados, para evitar que se trastoquen sus contenidos esenciales, sin embargo el número de reformas y su creciente extensión, motivada en gran medida por la propia transformación política y social han propiciado menor estabilidad, certeza y excesivo detalle en la regulación de su contenido, que desfavorecen su consolidación y vigencia plena de sus disposiciones.

Néstor Sagüés propone un nuevo concepto al tenor de estas ideas, entendido como desconstitucionalización, y que se asume como la pérdida de ciertos postulados clave del movimiento constitucionalista de la primera etapa, de corte liberal, como el principio democrático, el régimen representativo, o la división de poderes. Este fenómeno dice, se produce, por ejemplo, en la primera posguerra, en los estados totalitarios y autoritarios entonces en boga, Italia, Alemania, Unión Soviética, etcétera. ${ }^{8}$

Dicho autor, haciendo alusión a Linares Quintana9 ${ }^{9}$ nos indica algunas razones que provocaron la referida desconstitucionalización, entre algunos de los que menciona son:

[...]

c) La falta de coincidencia entre los textos constitucionales y las realidades locales[...]

8 Néstor Sagüés, La Constitución Bajo Tensión, Constitución y Democracia, Instituto de Estudios Constitucionales de Querétaro, México, 2016, pp. 98 y 99.

9 Segundo V. Linares Quintana, Tratado de la ciencia del derecho constitucional argentino y comparado, Buenos Aires, Plus Ultra, t. I, 198, pp. 183-193. 
d) Las luchas sociales, apuradas por las crisis económicas y falsamente resueltas por los enunciados líricos declamatorios incluidos en el papel de una Constitución.

Sin lugar a duda, el pensamiento liberal y la ideología del nuevo constitucionalismo abrieron paso a una nueva realidad política desde la constitución, trasladando fundamentos inmutables a una nueva visión compatible con la dignidad de las personas, los límites a la autoridad y las obligaciones de respeto y garantía de los Estados modernos.

Otro factor, apunta Sagüés al recordar a Karl Loewestein plantea el problema de la "desvalorización” de la Constitución escrita, preferentemente en el ámbito de las constituciones que denomina normativas, esto es las cumplidas u obedecidas en una proporción aceptable, no en la esfera de las constituciones nominales, cuya dosis de observancia es mínima, que importan un simple disfraz constitucional para encubrir hipócritamente situaciones de poder. ${ }^{10}$

Fix-Zamudio, señala que la consagración de los derechos humanos en los ordenamientos Latinoamericanos, se ha desarrollado de manera considerable en los últimos años. Si bien las cartas constitucionales expedidas los primeros años de la independencia de España establecieron los derechos clásicos individuales inspirados en la Declaración de los Derechos del Hombre y del Ciudadano, expedida por la Asamblea Nacional Francesa en 1789 y los introducidos por las Constituciones de los Estados en América del Norte, elevados posteriormente a la esfera Federal por las primeras enmiendas a la Constitución de 1787, que entraron en vigor en 1791, las leyes fundamentales latinoamericanas promulgadas durante el siglo XIX perfeccionaron dichos derechos clásicos e iniciaron los primeros intentos para regular los primeros instrumentos jurídicos para su

10 Néstor Sagüés sugiere revisar a Karl Loewenstein, Teoría de la Constitución, $2^{a}$. ed., traducción de Alfredo Gallego Anabitarte, Barcelona, Ariel, 1976, pp. 222 y ss. 
tutela tales como la revisión judicial de la constitucionalidad de las leyes de origen norteamericano, el hábeas corpus de creación inglesa y posteriormente el amparo inspirado en el modelo mexicano. ${ }^{11}$

Este elemento adicional del reconocimiento de libertades y derechos, trajo consigo una cohesión en los sistemas de protección, pero una verdadera tensión entre los postulados constitucionales y su confrontación, por ejemplo en el caso nuestro, con el corpus iuris interamericano, reubicando como eje rector a la persona y su dignidad y fragmentando las ideas planteadas por el prejurídico de 1917.

Lo anterior permite afirmar que las Constituciones al incluir catálogos específicos de instrumentos tantos sustantivos como adjetivos, logran definir conceptual y normativamente los alcances y límites de la actuación del Estado, por lo cual tal como indica Jesús González Pérez "la primacía de la dignidad de las personas es un principio general del derecho, uno de los principios formantes del ordenamiento jurídico español", ${ }^{12}$ refiriéndose al caso español.

Entre los cambios verdaderamente importantes cuentan la migración de las ideas constitucionales, ${ }^{13}$ la cual ha provocado un cambio de visión en el constitucionalismo moderno. Hoy en día es un hecho que muchos países comparten valores liberal-democráticos y, por ende, gran parte de las instituciones y concepciones que éstos generan. ${ }^{14}$

11 Héctor Fix-Zamudio, Los Derechos Humanos y su Protección Internacional, México, UNAM-Instituto de Investigaciones Jurídicas, IMPC, Grijley, 2009, p.14.

12 Jesús González Pérez, La dignidad de la persona, Civitas, Madrid, 1986, p. 85.

13 Sobre los pros y contras de la migración de las ideas constitucionales $\mathrm{N}$. Walker, The migration of constitutional ideas and the migration of the constitutional idea: the Case of the EU, EUI Working Paper Law n. 2005/04, Instituto Universitario Europeo, San Domenico, 2005.

14 Véase, Rodrigo Brito Melgarejo, El Diálogo entre los Tribunales Constitucionales, Biblioteca Porrúa de Derecho Procesal Constitucional, núm. 48, México, Porrúa, 2011 . 
No es casualidad que por un lado la Constitución nacional no alcanza a regular de manera omnicomprensiva y suprema el ejercicio del poder público sobre el territorio, admitiendo su parcialidad. A su vez, la "constitución supranacional" es también parcial, en la medida en que sólo puede regular sobre los ámbitos transferidos. Para obtener una imagen completa de la estructura del poder público ejercido en el territorio del Estado, se debe consultar tanto la constitución nacional como la supranacional. Entre estas normas no se establece una relación de jerarquía, sino de complementariedad. Cada una de estas normas tiene supremacía en el marco del ordenamiento correspondiente, pero las respectivas normas supremas no se ordenan jerárquicamente. ${ }^{15}$

La convivencia entre dos órdenes superpuestos, contrapuestos o integrados motiva una reflexión sobre los espacios pendientes de resolver y de las transformaciones que produce su existencia sobre todo a la voluntad inicial del constituyente, haciendo inaplazable su revalorización a la luz de los nuevos tiempos.

Aunado a lo anterior, los defectos formales y técnicos contribuyen de manera notable, al continuo proceso de reforma introducido en el texto constitucional vigente, que fomenta la erosión del mismo y nos lleva a cuestionar su plena vigencia, lograr la aproximación de la Constitución material con la Constitución real, en sí mismo constituye un desafío.

Entre dichos defectos, se encuentran, entre algunos; a) la presencia de disposiciones duplicadas, que permite su reiteración constante en diversos apartados de la Constitución sobre un mismo tema y que propicia confusión; b) uso variable e inconsistente de la terminología, al no existir compatibilidad entre algunos conceptos, ejemplos pueden ser, "derechos humanos", o "derechos fundamentales",

15 Aída Torres Pérez, "En defensa del Pluralismo constitucional", en Eduardo Ferrer Mac-Gregor y Alfonso Herrera García (coords.), Diálogo furisprudencial en de Derechos Humanos, entre Tribunales Constitucionales y Cortes Internacionales, México, Tirant Lo Blanch, 2013, p. 465. 
el lenguaje es vago, ambiguo e impreciso, o inclusive, podríamos indicar que es obsoleto al no contar con lenguaje incluyente que visibilice a las personas en igualdad de condiciones, en especial a los grupos en situación de vulnerabilidad; c) disparidad en el alcance y profundidad de la regulación, encontrando sustantivas diferencias por exceso o defecto en la regulación de instituciones que podrían ser de naturaleza semejante; d) falta de sistematización en la materia regulada en los artículos constitucionales lo que provoca un desorden; e) deficiente ubicación de las disposiciones constitucionales, en tanto persista la presencia de contenidos que se encuentran mal ubicados dentro de un artículo o fracción; f) errores en la actualización del texto, sugiriendo que cuando exista una modificación de algún artículo éste deberá adecuarse de manera transversal; g) artículos reglamentarios, en coherencia con lo indicado, el incremento de la regulación detallada ha ocasionado una excesiva dimensión de nuestro texto fundamental. ${ }^{16}$

En conclusión, dichos errores metodológicos y de contenido, han acarreado problemas severos que nos llevan a reconsiderar si la regla de reconocimiento actual tiene plena vigencia, efectividad, y desde el ángulo formal da respuesta a los problemas jurídicos que se le presentan, de este modo, el análisis sobre cuál es la razón que haya motivado el decaimiento del derecho y por ende de la norma de normas que legitima todo un sistema jurídico, además de validar y sancionar las normas que se encuentran contrapuestas a la misma.

Tal idea, genera una expectativa inicial que pueda ser resuelta a la luz de dos posibilidades, por una parte, si la Constitución no se presenta como un documento coherente con los nuevos tiempos, con la permeabilidad de diferentes conceptos y la idea de -living constitucion- generada a partir de la interpretación; segundo, si resulta compatible con la incorporación de cláusulas abiertas y de los

16 Se sugiere revisar, Constitución Política de los Estados Unidos Mexicanos, Texto Reordenado y Consolidado, Estudio Académico, México, Cámara de Diputados, UNAM, Instituto de Investigaciones Jurídicas de la UNAM, 2015. 
principios de universalidad, indivisibilidad, interdependencia y progresividad, y que hallen sentido a sus postulados, de no ser el caso, daría cabida al nuevo constituyente que revise de forma absoluta la Constitución de 1917 al tenor del propio marco constitucional originario.

Para el efecto de ello, Cárdenas Gracia dispone que se debe pensar en un constituyente que esté sujeto a límites temporales y axiológicos, que propicie las condiciones de un procedimiento democrático de revisión integral de la carta fundamental, sin olvidar los límites impuestos por el constituyente originario. ${ }^{17}$

Desde luego esta visión, inmersa en la discusión nacional, deberá contemplar las diferencias discutibles entre el proceso de consolidación de la actual Constitución y la alternativa de una nueva conformación, la primera se da como respuesta a los oprimidos en un contexto revolucionario, la segunda, tendría que considerar el propio marco constitucional impuesto por ella. En este supuesto, convendría situarnos entre las conveniencias y dificultades que dicho proceso de reforma total acarrearía para las instituciones, y desde luego en la dinámica política y social.

\section{LA CONSTITUCIÓN CONVENCIONALIZADA}

Una nueva propuesta de Constitución se originó con la reforma constitucional de 2011, cuyo objetivo principal fue dar reconocimiento a los derechos humanos y aproximarse a la idea contemporánea de protección y garantía a través de la inclusión a nivel constitucional de los tratados internacionales.

En este sentido, algunos autores se inclinan por señalar la existencia de una nueva Constitución, o bien una Constitución convencio-

17 Véase, Jaime Cárdenas Gracia, Poder Constituyente, Constitución y cambio democrático, Colección Derecho Procesal de los Derechos Humanos, número 6, UBIJUS, México, Instituto Interamericano de Derechos Humanos, Centro de Estudios de Actualización en Derecho, 2015, p. 37 y ss. 
nalizada, que podría entenderse como la norma fundamental con dos notas de actualización; a) depurada de sus cláusulas opuestas al derecho internacional de los derechos humanos y en particular, del Pacto de San José de Costa Rica y de la Jurisprudencia de la Corte Interamericana de Derechos Humanos, que pasan a ser reglas no operativas de la Constitución; b) reciclada conforme a aquéllos parámetros, mediante interpretaciones aditivas, sustractivas o mixtas del contenido del texto constitucional que la conformen con aquellos parámetros internacionalistas. ${ }^{18}$

En esta idea de nueva Constitución, los derechos se ven fortalecidos por aquéllas fuentes de derecho internacional, evitando complejas limitaciones en la lectura de la soberanía estatal y el positivismo tradicional, observando la uniformidad de la tendencia actual por superar esta preeminencia, así como el esfuerzo que se enfrenta de manera paulatina, en el análisis de la superioridad de la ley originaria frente a los tratados internacionales, propiciando un intento de integración que tenga por objetivo la progresividad de los derechos de las personas.

El beneficio de dicha integración permitirá inclusive el reconocimiento de los órganos internacionales de promoción y resolución de casos que se someten a su jurisdicción y el cumplimiento cotidiano que se realice de sus resoluciones. ${ }^{19}$

El fundamento axiológico de la Constitución convencionalizada se encuentra en la primacía del bien común regional o bien común internacional, sobre el bien común nacional, circunstancia que implica una profunda modulación, sobre este aspecto Morales Antoniazzi apunta al repensar la relación entre los distintos órdenes jurídicos, en razón de sus interacciones y la consecuente deconstrucción de la pirámide explicativa de la jerarquía normativa, por lo que emerge una nueva dogmática con base en un sistema jurídico

18 Néstor Sagüés, La Constitución Bajo Tensión, Constitución y Democracia, op.cit., p. 398.

19 Véase, Héctor Fix-Zamudio y Salvador Valencia Carmona, Derecho Constitucional Mexicano y Comparado, 5ª Edición, México, Porrúa-UNAM, 2007. 
plural en el que se entrecruzan principios, normas y regulaciones de los órdenes internacional, supranacional y estatal, fenómeno contemporáneo categorizado bajo distintas nociones como "acoplamiento", "redes horizontales de colaboración", "interconstitucionalidad", "meta constitucionalidad recíproca", "influjos y lecturas simultáneas", "multilevel constitucionalism", "normativismo supranacional", "transconstitucionalismo". Se está dibujando la figura geométrica del trapecio. ${ }^{20}$

En efecto, este nuevo sistema sometido a otros actores ajenos al constituyente originario, nos obligan a replantear la "crisis" por la que atraviesa la norma fundamental y su compatibilidad con nuevos instrumentos que son vinculantes y que obligan a una nueva aplicación e interpretación del sistema.

Salazar Ugarte, menciona que la disputa tiene que ver directamente con el tema del Ius Constitutionale Commune latinoamericano, el cual se refiere al alcance que deben tener las normas, discusiones y decisiones de las instancias regionales -en particular de la Corte Interamericana- en el ordenamiento jurídico y, a través de éste, en las dinámicas políticas y sociales en México. ${ }^{21}$

\section{iv. Contenido de una nueva constitución}

De una visión totalizadora, baste por ahora decir que los argumentos fundacionales promovidos por el constituyente originario y la concepción clásica en torno a las condiciones entre los individuos y el poder, al lado del aporte dogmático, en la actualidad, requiere dar respuesta a las múltiples cuestiones sobre la existencia de la Constitución como norma que determina todo un sistema jurídico,

20 Mariela Morales Antoniazzi, "El Estado abierto como objetivo del Ius Constitutionale", en Armin Von Bogdandy, et.al, Ius Constitutionale Commune en América Latina, pp.271-272.

21 Pedro Salazar Ugarte, "La disputa por los derechos y el Ius Constitutionale Commune", disponible en: <http://biblio.juridicas.unam.mx/libros/8/3655/6.pdf>. 
además de su carácter de superioridad del resto de las normas, sobre todo en casos donde pudiera representar una norma más limitada frente a un panorama de existencia de otras normas más favorables que garanticen los derechos en plenitud de las personas. ${ }^{22}$

En el ámbito de dichas discusiones, Jaime Cárdenas Gracia propone y señala que si nos inclinamos por la existencia de una nueva Constitución, deberá reflexionarse sobre los siguientes aspectos: a) Garantía plena de los derechos fundamentales, b) organización democrática de todo poder público nacional y la sustitución del sistema presidencial por uno parlamentario, c) supremacía constitucional, d) amplios mecanismos de defensa de la Constitución, e) Democracia participativa y deliberativa, f) medios e instituciones anticorrupción con amplios poderes, $g$ ) limitación y control efectivo a los poderes fácticos; $h$ ) defensa del patrimonio y de los recursos naturales de la nación, i) conclusión de la reforma en materia indígena, i) democratización y modernización del sistema federal y de los municipios.

La referida propuesta deberá tomar en cuenta los elementos formales y fácticos que posibiliten la realización de la misma, sobre todo asegurar que las normas constitucionales primigenias otorguen estabilidad y garantía a los procedimientos específicos a través de los cuáles se integre un documento nuevo, limitando el ejercicio de poder de los órganos constituidos que pudieran menoscabar esa libertad consagrada en 1917.

El presupuesto principal en esta nueva idea consistirá en concebir una alternativa propicia que lejos de fragmentar el sistema jurídico mexicano, permita amalgamar con los instrumentos internacionales, provocando así el progreso de la sociedad y del Estado.

Tener en cuenta dos dimensiones radicales, Estado y sociedad, en la tendencia de crear una nueva Constitución deberá considerar de manera inmediata, al órgano especial, denominado constituyente,

22 Véase, Engrose contradicción de tesis 293/2011. 
que instrumente los procedimientos necesarios para su integración, en simetría con dicha situación, atenderá a la incorporación de la participación ciudadana a través de mecanismos idóneos y desde luego los límites explícitos para las modificaciones futuras.

Cárdenas prosigue, que cuando se plantea una nueva Constitución o se propone una revisión integral, deberá darse respuesta a seis preguntas básicas: a) el órgano que debe hacer la reforma constitucional; b) la conveniencia de instaurar un procedimiento o varios para las reformas constitucionales futuras; c) el nivel de rigidez de estas reformas; d) la participación popular en todo procedimiento de reforma constitucional; e) los límites explícitos para las reformas constitucionales futuras, y desde luego, f) la existencia de límites implícitos. ${ }^{23}$

Sumado a lo anterior, la razón de esta nueva forma de entender al derecho constitucional, conllevaría además de todos los elementos añadidos al problema planteado, a identificar la existencia de un pluralismo constitucional, originadas en gran parte por la globalización, internacionalización, mundialización y transconstitucionalización.

En coherencia con tales argumentos, resultará indispensable discutir sobre el órgano denominado constituyente y su legitimidad "constitucional y democrática" para convocar a la integración de un nuevo texto, su naturaleza opuesta a la del prejurídico de 1917, concretado por una lucha social que motivó su existencia, pero que diferiría del que se proponga en la actualidad porque éste último actuaría en un marco legal y constitucional, es decir la propia Constitución en vía de remisión tendría que otorgarle los lineamientos para la elaboración de la carta magna, evitando con ello la regresividad.

23 Cfr., Jaime Cárdenas Gracia, Poder Constituyente, Constitución y cambio democrático, Colección Derecho Procesal de los Derechos Humanos, op.cit., p. 43. 
Ha de tratarse además, por ejemplo los elementos que motivan que aquélla idea propuesta a más de cien años, resulte solo una aspiración, lo anterior confrontado con los resultados de la Tercera Encuesta Nacional de Cultura Constitucional: los mexicanos y su Constitución, elaborada por el departamento de Investigación Aplicada y Opinión del Instituto de Investigaciones Jurídicas de la UNAM en homenaje a la Constitución de 1917, en el centenario de su promulgación.

Dicha encuesta afirma que el 84 por ciento de los mexicanos considera que la Constitución se cumple poco o nada; 56.1 por ciento dice conocer poco de la Carta Magna y 52.7 desconoce el año en que se aprobó y no la relaciona con la Revolución Mexicana, estos resultados nos dan indicios para entender la "escasa" o nula cultura de constitucionalidad.

Además, uno de cada cuatro mexicanos piensa que "violar la ley no es tan malo, lo malo es que te sorprendan"; el 46.6 por ciento dice que los miembros de una comunidad tienen el derecho de tomar justicia por mano propia; y 27.3 por ciento está de acuerdo con que un funcionario público puede aprovecharse de su puesto si hace cosas buenas.

Esta encuesta - aplicada a nivel nacional en mil 200 casos en vivienda a población de 15 años y más, en octubre de 2016- es la tercera de una serie iniciada en 2003, y ofrece, según la propia Universidad, la posibilidad de mirar la evolución de los saberes y opiniones de los mexicanos sobre su Constitución, el cumplimiento de la ley y la democracia.

No obstante, 43 por ciento señaló que sería preferible cambiarla sólo en parte, dado que ciertos principios y artículos, como por ejemplo el tercero, están presentes en la memoria de la población. ${ }^{24}$ Este último enunciado estima que un sector importante de la población tiene identidad con la norma fundamental, pero desconoce su

24 Boletín UNAM-DGC-083, Ciudad Universitaria, 5 de febrero de 2017, disponible: <http://www.dgcs.unam.mx/boletin/bdboletin/2017_083.html>. 
contenido y alcances, e incluso no comparten la intención de crear una nueva norma, atendiendo a que comprende una disposición de carácter patrimonial.

En razón de tal afinidad, empero la Constitución de 1917 fue presentada como el producto de la identificación de las demandas sociales, sin embargo el desorden, falta de sistema y reordenación, motivan la disparidad en su objetivo principal y la convierten más en un instrumento que concentra los intereses de los factores reales de poder.

La Constitución, expresa la Tercera Encuesta de Cultura Constitucional, ${ }^{25}$ es un punto de contacto, una estructura, que vincula al orden jurídico con el campo del poder, y ello exige estudiar su significado desde ambos ángulos disciplinarios, cuando menos en las sociedades contemporáneas, la Constitución es un punto de referencia del comportamiento y de la organización sociales, sobre todo en la medida en que hay un ambiente crecientemente plural $y$, por consiguiente, en el que los ciudadanos encuentran cada vez menos puntos de contacto e identidad política, religiosa y ética con los demás integrantes de la comunidad.

Dicho en otras palabras según el estudio de opinión referido, la Constitución asume una función tanto más relevante cuanto más se requiera definir un orden que goce de un consenso básico, aunque relativo, que sirva de marco y guía tanto para las instituciones como para los individuos.

Un segundo orden de consideraciones, es evaluar las exigencias en las que se ve inmerso el texto actual, no contempladas hace un centenar de años, así este modo el uso en la práctica diaria de su funcionamiento de ideas tales como derechos fundamentales, divi-

25 Héctor Fix-Fierro, Julia Isabel Flores y Diego Valadés, Los mexicanos y su Constitución. Tercera Encuesta de Cultura Constitucional, centenario de la Constitución de 1917, Biblioteca los mexicanos vistos por sí mismos, los grandes temas nacionales, Universidad Nacional Autónoma de México, 2017. Disponible en: <http://www. losmexicanos.unam.mx/MexicanosConstitucion/index.html>. 
sión de poderes, primacía, democracia, control de constitucionalidad, entre algunas, es consecuencia de una suerte de mutación en su naturaleza que sin eliminar su carácter internacional les ha acercado mucho a las formas de ejercicio del poder tradicionalmente reservadas a los Estados y objeto, por ello, de normas de naturaleza constitucional y no sólo iusinternacional. ${ }^{26}$

Si a lo anterior le sumamos las nuevas atribuciones que tienen los órganos judiciales, especialmente aquéllos denominados "constitucionales", podríamos reflexionar en esta posibilidad de conformación del nuevo texto constitucional, que ligado a otros instrumentos permita el despliegue y desarrollo de las instituciones y sobre todo absorba estos cambios sustantivos, motivados en gran medida por el influjo de los sistemas internacionales.

En simetría con lo anterior, el proyecto de una nueva Constitución tendría que considerar cuáles debieran ser los lineamientos para convocar a la Asamblea Constituyente, cuál debe ser la participación de las entidades federativas y si dicho documento se sometería a algún tipo de mecanismo de revisión social, por ejemplo, alguna de las técnicas de democracia directa.

Deberá tener en cuenta, además, los procedimientos, de ser el caso para la reforma total a la Constitución, las fórmulas a las que puede recurrir para dificultar su reforma, la fijación de un proceso agravado para su modificación, excluyendo la incorporación de fuerzas de poder que materialicen sus intereses y no los de la sociedad.

Para lo anterior deberá tomarse en cuenta, según la obra de Cárdenas Gracia:

1. Se adicionaría el artículo 135 para establecer en un párrafo tercero el procedimiento de reforma total a la Constitución.

26 Rafael Bustos Gisbert, Pluralismo Constitucional y Diálogo Furisprudencial, Biblioteca Porrúa de derecho Procesal Constitucional, núm. 52, México, Porrúa, 2011, pp. 14-15. 
2. El procedimiento iniciaría con la aprobación de la ley de consulta, la que contendría el proyecto de texto constitucional que haya sido aprobado previamente por la Ponencia Constitucional. La ley de consulta requerirá ser aprobada por la mayoría de los individuos presentes en cada Cámara de Congreso y por el cincuenta por ciento más uno de las legislaturas locales.

3. Aprobada la ley de consulta, ésta se hace al pueblo en los dos meses siguientes.

4. La Asamblea constituyente estaría integrada por 500 diputados elegidos bajo el esquema actual de integración de esa Cámara y se instalará un mes después de celebrada la consulta. Dicha Asamblea discutirá, en su caso aprobará, modificará o rechazará el proyecto de texto constitucional elaborado por la ponencia Constitucional. En dicha ponencia se representará a todos los grupos parlamentarios y estará integrada por la mitad del grupo de legisladores que conforman la comisión permanente. La aprobación requerirá de las dos terceras partes de los votos totales de los legisladores constituyentes.

5. Una vez aprobado el texto constitucional, se someterá previa convocatoria de este órgano, a referéndum.

6. La Asamblea Constituyente no podría contar con más de seis meses para aprobar el texto constitucional.

7. La presente Constitución y las leyes mantendrán plenamente su vigencia durante el tiempo que sesione el Congreso Constituyente. ${ }^{27}$

Si bien la propuesta presentada goza de coherencia y plantea legitimidad democrática que garantice transparencia y certeza de

27 Jaime Cárdenas Gracia, Poder Constituyente, Constitución y cambio democrático, Colección Derecho Procesal de los Derechos Humanos, op.cit., pp. 62-66. 
legalidad, lo cierto es que presenta algunas dificultades considerables que tendrían que tomarse en cuenta, vale la pena indicarlas:

1. La existencia de nuevos procesos democráticos que dan posibilidad a candidatos independientes para intervenir en las decisiones públicas actualmente y que no ciertamente participan de alguna fracción parlamentaria en sentido estricto, pues representan los intereses sociales. Los acuerdos de las fuerzas políticas existentes también constituyen una preocupación.

2. El papel de la Suprema Corte de Justicia de la Nación se ve cuestionado al tenor de la doctrina de los denominados "tribunales constitucionales", cuyo papel fundamental es ser los guardianes del texto constitucional, conviene entonces analizar, cuál sería la participación de nuestro tribunal pleno, considerando que el constituyente original no le reconoció esa calidad, pero que materialmente a través del conocimiento de procesos especializados, tales como las acciones de inconstitucionalidad, las controversias constitucionales y el amparo, delimitan las atribuciones de los órganos de poder y representa un verdadero guardián del texto fundamental. La doctrina se inclina en pensar que los tribunales constitucionales a diferencia de los otros órganos de poder, se caracterizan por su conocimiento especializado, lo cual favorece el cumplimiento de las tareas asignadas.

3. La participación del Ejecutivo Federal es cuestionable, la convocatoria a elecciones de la Asamblea constituyente deberá realizarse bajo los procedimientos más estrictos y transparentes, que garanticen la objetividad y sobre todo la democracia. 4. La existencia de un amplio catálogo de derechos que se ven sometidos al análisis de órganos internacionales deberá representar un eje rector, sobre todo si tenemos en cuenta que existen órganos permanentes de vigilancia a los que nos encontramos sometidos por voluntad del Estado, especialmente 
la Corte Interamericana de Derechos Humanos, existen numerosos principios de derecho internacional que deberán ser recogidos en el nuevo texto constitucional, para evitar incurrir en una responsabilidad de carácter trasnacional.

El largo camino que enfrenta esta propuesta podría resolverse a través de la reordenación, sistematización y creación de leyes de desarrollo constitucional, que bajo un esquema menos abrumador permitan la eficacia y cumplimiento de la norma fundamental, pero que sobre todo respeten la voluntad asumida en 1917, es decir no se alterarían ni modificarían los principios bajo los cuales se integró la norma de especial valor en nuestro sistema.

\section{v. Conclusiones}

La pregunta planteada en el exordio del presente trabajo constituye el eje rector de la investigación, si bien la doctrina sobre la que se ha construido el derecho mexicano se encuentra anclado en los postulados del constitucionalismo, lo cierto es que también representa nuevos desafíos que deben ser sometidos a valoración.

Para este fin se informa que de manera progresiva nuestra carta fundamental ha experimentado cambios notables por las vías permitidas bajo sus propias reglas, en muchos casos no existe claridad sobre la necesidad y oportunidad para llevarlos a cabo.

En años recientes, se presenta un nuevo fenómeno discutible en manos de los factores reales de poder que intervienen a través de sus intereses en la excesiva modificación de nuestra norma fundante, que originó un texto cada vez más ajeno a nuestra realidad.

El incremento de la reglamentación a detalle plasmada en la ley fundamental provoca una norma muy amplia, con lenguaje técnico, expresiones jurídicas especializadas que dan como resultado una cultura constitucional cada día más deficiente. 
El estudio realizado por la UNAM señala que en 1917 el documento constitucional tenía 21 mil palabras de extensión, para 1982 el texto había alcanzado casi las 30 mil palabras, con efecto de una modernización constitucional en la etapa presidencial de Miguel De la Madrid se inicia un crecimiento más rápido, que se hace vertiginoso con los periodos de Felipe Calderón y Enrique Peña Nieto, aumentando una extensión del texto constitucional a casi tres veces. ${ }^{28}$

Bien puede argumentarse con lo anterior, la necesidad de una nueva Constitución, proyecto que consideramos resulta poco conveniente, sobre todo si tenemos en cuenta las complejas interacciones políticas que en sí mismo el proceso acarrearía, la falta de consensos, la transparencia y sobre todo el debilitamiento de la conciencia constitucional escasa que a la fecha se tiene.

Por todas esas razones nos inclinamos en apuntar a que la respuesta se encuentra sobre todo en la ordenación, sistematización y creación de leyes de desarrollo constitucional, como un ejercicio que ofrezca certidumbre y seguridad, sin que se trastoquen los principios originarios que dieron paso a la integración de nuestra Nación.

Más aun, es rescatable esta posibilidad en la medida que, a juicio de muchos autores, la nuestra representa una de las constituciones más modernas en toda Latinoamérica, sobre todo a la luz de los nuevos planteamientos otorgados a partir de 2011.

Si bien existen motivos de sobra para considerar dicha idea, los cierto es que también podríamos ser optimistas al pensar en lo fortalecidos que se encuentran los derechos fundamentales a partir de la convencionalización de nuestra norma interna, las nuevas fronteras y los roles asumidos en este nuevo escenario.

28 Fix-Fierro y Diego Valadés (coords.), Texto reordenado y consolidado, Estudio Académico, México, Universidad Nacional Autónoma de México, Instituto de Investigaciones Jurídicas de la UNAM, Cámara de Diputados, 2015, p. 15. 
Conviene agregar que, si bien la propuesta de un nuevo texto normativo presentada por algunos expertos busca conciliar la constitucionalidad vigente con la futura, nos inclinamos en pensar que la propuesta entraña una ruptura con los postulados genuinos motivados por la revolución, los cuales podrían conservarse si se optara por la reordenación como una salida novedosa en la nueva teoría constitucional.

\section{Vi. BibLIOGRAFía}

Albanese, Susana (coord.),Opiniones consultivas y observaciones generales, Control de Convencionalidad, Buenos Aires, Ediar, 2011.

Astudillo, César, El bloque y parámetro de constitucionalidad en México, México, Tirant Lo Blanch, 2014.

Bustos Gisbert, Rafael, Pluralismo Constitucional y Diálogo Furisprudencial, Biblioteca Porrúa de derecho Procesal Constitucional, núm. 52, México, Porrúa, 2011.

Cárdenas Gracia, Jaime, Poder Constituyente, Constitución y cambio democrático, Colección Derecho Procesal de los Derechos Humanos, número 6, UBIJUS, Instituto Interamericano de Derechos Humanos, Centro de Estudios de Actualización en Derecho, México, 2015.

Ferrer Mac-Gregor, Eduardo y Herrera García, Alfonso (coords.), Diálogo Furisprudencial en de Derechos Humanos, entre Tribunales Constitucionales y Cortes Internacionales, México, Tirant Lo Blanch, 2013.

- El control difuso de convencionalidad. Diálogo entre la Corte Interamericana de Derechos Humanos y los jueces Nacionales, México, Fundap, 2012.

Fix-Fierro, Héctor, Flores, Julia Isabel, y Valadés, Diego, Los mexicanos y su Constitución. Tercera Encuesta de Cultura Constitucional, centenario de la Constitución de 1917, Biblioteca los mexicanos vistos por sí mismos, los grandes temas nacionales, México, Universidad Nacional Autónoma de 2017. 
- y Valadés, Diego (Coords.), Texto reordenado y consolidado, Estudio Académico, México, Universidad Nacional Autónoma de México, Instituto de Investigaciones Jurídicas de la UNAM, Cámara de Diputados, 2015.

Fix-Zamudio, Héctor, Los Derechos Humanos y su Protección Internacional, México, UNAM-Instituto de Investigaciones Jurídicas, IMPG, Grijley, 2009.

- y Valencia Carmona, Salvador, Derecho Constitucional Mexicano y Comparado, 5a . Edición, México, Porrúa-UNAM, 2007.

González Pérez, Jesús, La dignidad de la persona, Madrid, Civitas, 1986.

Loewenstein, Karl, Teoría de la Constitución, 2a . Ed., trad. Alfredo Gallego Anabitarte, Barcelona, Ariel, 1976.

Philip, Jessup C.; Transnational Law; Yale University Press, Geoffrey Cumberlege, Oxford, New Haven, 1956.

Sagüés, Néstor, La Constitución Bajo Tensión, Constitución y Democracia, México, Instituto de Estudios Constitucionales de Querétaro, 2016. 